\title{
Identification of the Factors Effective on Increase of Staff Productivity in Iran Electrical Development Organization's Central Office
}

\author{
${ }^{1}$ Zeinolabedin amini sabegh, ${ }^{2}$ sirius tadbiri, ${ }^{3}$ Reza Shafizadeh, \\ ${ }^{4}$ Hengameh Rahimi \\ ${ }^{1,2,3}{ }^{\text {Departmen }}{ }^{t}$ of Public management, Science and Research branch, Islamic Azad University, Saveh, Iran \\ ${ }^{4}$ Student of Public management, Science and Research branch, Islamic Azad University, Saveh, Iran.
}

\begin{abstract}
Several years have passed since the discussion around productivity has begun amid the scientific and social discussions of Iran. In the world's fast-moving competition stage and the accelerating course of technology, policymakers and managers now pay attention to improvement of productivity sometimes as tools and sometimes as goals. This research study addresses 4 effective factors on productivity through the correlation analysis. The statistical population includes the employees of the central office working in Iran Electrical Development Organization, who have been selected randomly, and their viewpoints were obtained by using the questionnaire. The results of research prove that paying attention to fundamental needs of the employees, their participation in decision-makings, staff teamwork in the work environment, and payment of fringe benefits to the employees will increase their productivity in the work environment. Further, as viewed by people with different educational levels and gender, the indices effective on productivity are different from each other.
\end{abstract}

Keywords: Productivity, Participation, Performance Analysis

\section{Introduction}

No doubt that the economic growth of societies relies on the rate of productivity improvement. The experimental studies in advanced industrial countries reveal that the importance of productivity, as a result of development of management software systems, is more than participation and quantitative increase of labor and circulating capital. Productivity is always the result of a series of interfering variables that dims its light. Such factors as low quality of performance, ineffective structure, weak managerial systems, lack of competence-based management, lack of suitable cultural grounds for execution of the productivity projects, staff's job dissatisfaction, job instability of the managers and employees, lack of trust among managers and employees, shortage of proper and up-to-date trainings in the area of productivity, having no long-range outlook in management, organization's unclear missions, shortage of occupational ethics among employees, fadeout of staff participation system within the organization, disqualified management system and other reasons, have all turned productivity into a complicated variable. The main issue of discussion in this research is to study and determine the effective factors on productivity in Iran Electrical Development Organization.

\section{Research Questions}

Main Questions:

What are the factors effective on increasing productivity among Iran Electrical Development Organization's employees?

\section{Secondary Questions:}

1- Does improvement of motivation among employees increase their productivity?

2- Does establishment of a suitable payroll system increase their productivity?

3 - Does development of knowledge increase the employee's productivity?

4- Does employees' participation increase their productivity?

\section{Research Methodology}

This is an applied and survey research. Likert 5-option questioners and documents have been used in order to collect data. Nonparametric statistics have also been used for data analysis. The statistical population in this research includes all employees in the Staff Department of Iran Electrical Development Organization, who have been counted to be 395 persons based on the 2011 census. 


\section{Conclusion}

After conducting the first hypothesis test, since the level of significance for Pearson test is equal to 0.047 and is less than 0.05 , as a result there is a significant relation between the effective factors on productivity and the organizational productivity.

After testing the sub-hypothesis 1 , since the level of significance of the Pearson test is equal to 0.033 and is not less than 0.05 , there is thus no significant relation between the motivation and variable organizational productivity. After testing the sub-hypothesis 2 , since the level of significance for Pearson test is equal to 0.045 and is not less than 0.05 , as a result there is a significant relation between the payment system and variable organizational productivity. After testing the sub-hypothesis 3 , since the level of significance for Pearson test is equal to 0.014 and is less than 0.05 , so there exists a significant relation between the knowledge development and variable organizational productivity. After testing the sub-hypothesis 4 , since the level of significance for Pearson test is equal to 0.026 and is less than 0.05 , as a result there is a significant relation between the participation and variable organizational productivity.

\section{Reference}

[1]. Kilic, Hasan and Fevzi, Okumus. (2005)."Factors Influencing Productivity In Small Island Hotels", International Journal of Contemporary Hospitality Management, VOL. 17, NO. 4, PP. 315-331.

[2]. Tangen, Stefan (2005). “Perofissional Practice Demystifying Productivity And Preformance ”, International Journal of Productivity And Performane Management, Vol.54,No.1

[3]. Grafton, Q., Kirkley, J., Kompas, T. and Squires, D. (2006), Economics for Fisheries Management, Ashgate Publishing Ltd.

[4]. Eastough, K. and Miller, P. (2004), 'The gender wage gap in paid and selfemploymentin Australia', Australian Economic Papers, vol. 43, no. 3,pp 257-276. 